www.jmscr.igmpublication.org

Index Copernicus Value: 79.54

ISSN (e)-2347-176x ISSN (p) 2455-0450

crossref DOI: https://dx.doi.org/10.18535/jmscr/v7i6.45

Journal Of Medical Science And Clinical Research

IGM Publication

An Official Publication of IGM Publication

\title{
Contraception among the mothers attending a tertiary care hospital of Kolkata
}

\author{
Authors \\ Dr Sonali Sain ${ }^{1}$, Dr Indira Dey ${ }^{2 *}$, Dr Prianka Mukhopadhyay ${ }^{1}$ \\ ${ }^{1}$ Assistant Professor, Department of Community Medicine, NRS Medical College, West Bengal, India \\ ${ }^{2}$ Associate Professor, Department of Community Medicine, NRS Medical College, West Bengal, India \\ *Corresponding Author \\ Dr Indira Dey \\ 29 A, Kali Kumar Banerjee Lane, Kolkata-700002, West Bengal, India
}

\begin{abstract}
Background: India was the first country in the world to launch the National Family Planning Programme, still we are lagging behind the target.

Objectives: To find out current contraceptive practice among the mothers attending a tertiary care hospital and to assess the factors contributing to the poor contraceptive practices.

Methodology: A descriptive cross sectional study was conducted in NRS Medical college and Hospital, Kolkata. Mothers who had attended the postpartum and immunization clinic from November to December 2017 were selected for the study after obtaining informed verbal consent. 280 study subjects were fulfilled the inclusion criteria were interviewed by predesigned, pretested, semistructured questionnaire and data was collected regarding sociodemographic profile, current and ever use of contraceptives and reasons for not using any scientific methods. All collected data was compiled and analysed by MS Excel 8.0 and Epi info3.4.3

Results: Majority (72.14\%) of the study population had knowledge of family planning methods, but only $123(43.93 \%)$ were currently using any form of modern contraception. Maternal age, residence and occupation was found to be significantly associated with contraceptive practices. $95.12 \%$ of mothers were counselled regarding contraceptive methods during their hospital visit but $25.20 \%$ were counselled about the side effects of the methods chosen. Only $66.42 \%$ of mothers were counselled during antenatal visit.

Conclusion: Increase in awareness and change in attitude regarding contraception will help India to reach out the missed target of population stabilization.

Keywords: unmet need, contraception, family planning, postpartum mothers.
\end{abstract}

\section{Introduction}

In 1951, India became the first country in the world to launch a family planning programme. Since then approaches for reducing population growth have taken a variety of forms.

Family planning is a way of thinking and living that is adopted voluntarily, upon the basis of knowledge, attitudes and responsible decisions by individuals and couples, in order to promote the health and welfare of the family group and thus contribute effectively to the social and economic development of a country. Contraception is, by definition, preventive methods to help women avoid unwanted pregnancies. ${ }^{1}$ 
Contraception in post partum women is essential, because post partum women are at a high risk of unplanned pregnancies especially in the 1 st year after delivery, adoption of postpartum contraceptives leads to not only a reduction in unplanned pregnancies, but also improves maternal and child well-being. Since short birth intervals of less than 15 months are associated with adverse pregnancy outcomes like induced abortions, miscarriage, preterm births, neonatal and child mortalities. ${ }^{2}$

Although there are multiple contacts between women and healthcare providers during the postpartum period, when women are seeking child immunization services, yet the unmet need for contraception is still high.,

While family planning (FP) is important throughout an individual's and couple's reproductive life, postpartum family planning (PPFP) focuses on the prevention of unintended and closely spaced pregnancies through the first 12 months following childbirth. ${ }^{5}$

The current study was conducted to find out current contraceptive practice among the mothers attending the postpartum unit and immunization clinic of NRS Medical College and Hospital and also to assess the factors contributing to the poor contraceptive practices.

\section{Methodology}

A descriptive cross sectional study was conducted in the post partum unit and immunization clinic of a tertiary hospital of Kolkata. Mothers who had attended the clinic from November to December 2017 were selected for the study after obtaining informed verbal consent. Those who were not willing to give consent were excluded from the study. Ethical permission was obtained from Institution Ethics Committee.

280 study subjects were selected consecutively among those who gave consent and fulfilled the inclusion criteria over 2 months period. During study, mothers were interviewed by predesigned, pretested, semistructured questionnaire after translating into local language and data was collected regarding sociodemographic profile, current and ever use of contraceptives and reasons for not using any scientific methods. All collected data was compiled and analysed by MS Excel 8.0 and Epi info 3.4.3. Results were presented as percentages \& proportions and Chi square test was applied as the test of significance.

\section{Results}

During the present study, 280 mothers attending the postpartum clinic and immunization clinic of NRS Medical College and hospital were considered during their visit. The study subjects were among the age group of $17-40$ years with and mean value of 23.92 years. Among this, $11.78 \%$ were teenage mothers. 73.92 were Hindu, $53.57 \%$ from urban area, $2.14 \%$ illiterate and $88.57 \%$ homemakers. $50.71 \%$ were from nuclear family. $65.67 \%$ were from social class of middle class and above. $48.56 \%$ of mothers were multipara.43.57\% of study subjects came for family planning practices, $18.93 \%$ for immunization of baby, $37.5 \%$ for postnatal care and $0.71 \%$ for post abortion care.

Although majority 202 (72.14\%) of the study population had knowledge of family planning methods, but only 123 (43.93\%) were currently using any form of modern contraception ( Fig :1) . Among them 44.71 were pill users, followed by $26.84 \%$ of IUD user, $12.20 \%$ of Injectable methods and only $6.50 \%$ had undergone permanent methods like sterilisation. $52.67 \%$ of mothers did not use contraception as they wanted to conceive. Factors contributing to poor contraceptive practice among the non users were health concerns $(14.5 \%)$ including menstrual irregularity, $12.97 \%$ had missed pill or missed injection, $6.87 \%$ had fear of adverse outcomes, and $5.34 \%$ reported inconvenience related to the contraceptive methods.

Present study showed that contraception use increased with the increase of age. It was found less teenage mothers used any form of contraception whereas more older mothers (>30 years) used contraception. This difference was 
statistically significant. Use of contraception was found to be significantly more in rural areas compared to urban areas. The significant difference was found among homemakers and working mothers. Difference among type of family, educational status and socioeconomic status were found to be statistically not significant. (Table:1)
Only $66.42 \%$ of mothers were counselled regarding contraception during antenatal visit. But $95.12 \%$ of mothers were counselled while they were provided any contraceptive methods. Among those who were counselled (123), $25.20 \%$ were counselled about the side effects of the methods chosen and $35.03 \%$ were briefed about the missed pill regimen.

Fig:1 Distribution of mothers according to current use of contraceptive methods

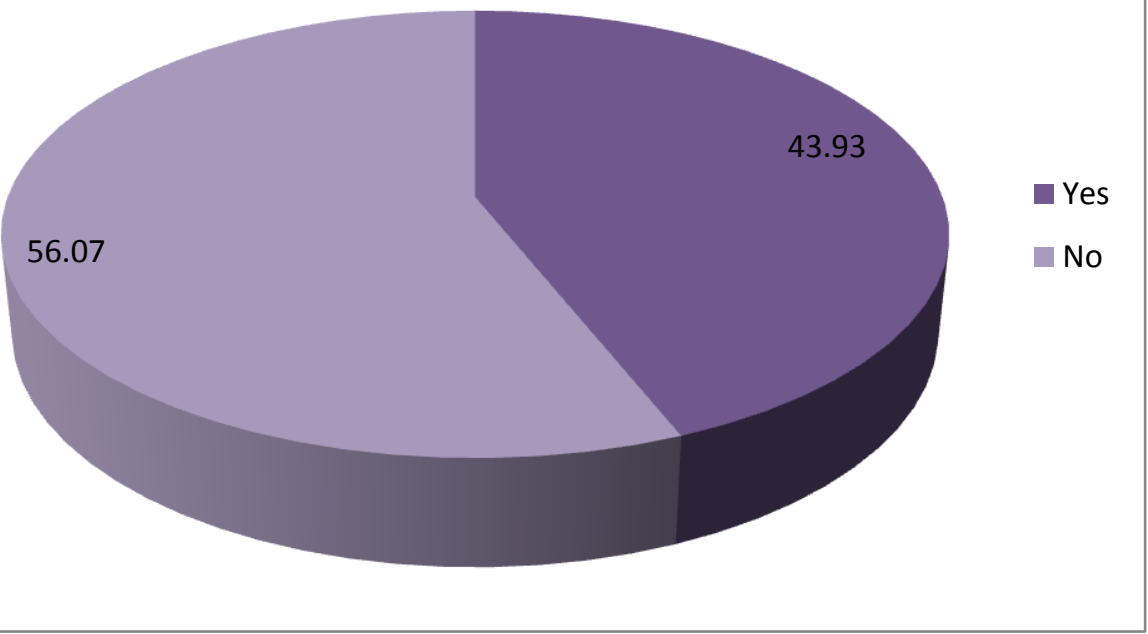

Table 1: Distribution of study population according to Sociodemographic Profile and Contraception use

\begin{tabular}{|c|c|c|c|c|}
\hline \multirow{2}{*}{$\begin{array}{l}\text { Sociodemographic } \\
\text { profile }\end{array}$} & \multicolumn{2}{|c|}{ Contraceptive use } & \multirow{2}{*}{$\begin{array}{l}\text { Total } \\
(280)\end{array}$} & \multirow[t]{2}{*}{ Statistical Test } \\
\hline & User (123) & Nonuser (157) & & \\
\hline Age ( in years): & No. (\%) & No. (\%) & No. (\%) & \multirow{4}{*}{$\begin{array}{c}\mathrm{X}^{2}=17.703 \\
\mathrm{df}=2 \\
\text { P value }=\mathbf{0 . 0 0 1 4 3}\end{array}$} \\
\hline$<20$ & $10(8.13)$ & $23(14.64)$ & $33(11.78)$ & \\
\hline $20-30$ & $95(77.24)$ & $131(83.43)$ & $226(80.72)$ & \\
\hline$>30$ & $18(14.63)$ & $3(1.91)$ & $21(7.50)$ & \\
\hline \multicolumn{5}{|l|}{ Religion: } \\
\hline Hindu & $99(80.49)$ & $108(68.79)$ & $207(73.92)$ & \multirow{3}{*}{$\begin{array}{l}X^{2}=5.799 \\
d f=2 \\
P \text { value }=0.055\end{array}$} \\
\hline Muslim & $24(19.51)$ & $47(29.94)$ & $71(25.37)$ & \\
\hline Christian & $0(0)$ & $2(1.27)$ & $2((0.71)$ & \\
\hline \multicolumn{5}{|l|}{ Residence: } \\
\hline Rural & $33(26.83)$ & $97(61.78)$ & $130(46.43)$ & \multirow{2}{*}{$\begin{array}{l}X^{2}=33.879 \\
d f=1 \\
P \text { value }=\mathbf{0 . 0 0 0 0}\end{array}$} \\
\hline Urban & $90(73.17)$ & $60(38.22)$ & $150(53.57)$ & \\
\hline \multicolumn{5}{|c|}{ Educational Qualification: } \\
\hline Illiterate & $0(0)$ & $6(3.82)$ & $6(2.14)$ & \multirow{5}{*}{$\begin{array}{l}X^{2}=7.013 \\
d f=4 \\
P \text { value }=0.1352\end{array}$} \\
\hline Primary & $2(1.63)$ & $5(3.18)$ & $7(2.5)$ & \\
\hline Middle & $24(19.51)$ & $38(24.21)$ & $62(22.14)$ & \\
\hline $\begin{array}{l}\text { Secondary and } \\
\text { Higher secondary }\end{array}$ & $78(63.41)$ & $87(55.41)$ & $165(58.93)$ & \\
\hline Graduate and above & $19(15.45)$ & $21(13.38)$ & $40(14.29)$ & \\
\hline
\end{tabular}




\begin{tabular}{|c|c|c|c|c|}
\hline \multicolumn{5}{|l|}{ Occupation: } \\
\hline Homemaker & $115(93.50)$ & $133(84.71)$ & $248(88.57)$ & \multirow{2}{*}{$\begin{array}{l}X^{2}=5.2554 \\
d f=1 \\
P \text { value }=\mathbf{0 . 0 2 1 8}\end{array}$} \\
\hline Working & $8(6.50)$ & $24(15.29)$ & $32(11.43)$ & \\
\hline \multicolumn{5}{|l|}{ Type of Family: } \\
\hline Nuclear & $70(56.91)$ & $72(45.86)$ & $142(50.71)$ & \multirow{2}{*}{$\begin{array}{l}X^{2}=3.3696 \\
d f=1 \\
P \text { value }=0.066\end{array}$} \\
\hline Joint & $53(43.09)$ & $85(54.14)$ & $138(49.29)$ & \\
\hline \multicolumn{5}{|c|}{ Socioeconomic status:* } \\
\hline Upper Class & $1(0.81)$ & $3(1.91)$ & $4(1.43)$ & \multirow{5}{*}{$\begin{array}{l}X^{2}=7.95 \\
d f=4 \\
P \text { value }=0.09\end{array}$} \\
\hline Upper Middle Class & $35(28.46)$ & $32(20.38)$ & $67(23.93)$ & \\
\hline Middle Class & $48(39.02)$ & $63(40.13)$ & $111(39.64)$ & \\
\hline Lower Middle Class & $36(29.27)$ & $44(28.02)$ & $80(28.57)$ & \\
\hline Lower Class & $3(2.44)$ & $15(9.56)$ & $18 \quad(6.43)$ & \\
\hline
\end{tabular}

According to Modified B.G.Prasad Scale 2018

\section{Discussion}

Although India is the first country in the world to launch family planning programme, but target is not achieved till now. Unmet need of family planning is an important contributing factor in this scenario. This can be achieved by improved quality of family planning services. These are important means of increasing knowledge of contraception and changing attitude towards adopting an effective contraceptive methods.

Among the mothers attending postpartum unit and immunization clinic, $43.93 \%$ used any form of contraceptive methods. But NFHS IV report of West Bengal showed higher prevalence $(57 \%)$ of any method of contraception among 15- 49 years currently married women. ${ }^{6}$ Similar study conducted in South Bengal found much higher prevalence of $67.4 \%$ among the currently married women of reproductive age group. ${ }^{7}$ But Mexican Study found similar prevalence of modern contraceptive methods of $47 \%$. ${ }^{8}$ This difference may be due to the difference in study population and many of the mothers attending the clinic in the present study were in post partum period. But two thirds of women who are within a year of their last child birth had unmet need for contraception, found by another research conducted in Mexico. ${ }^{9}$

Regarding common method of contraception used, 44.71 was OC pill, followed by $26.84 \%$ of IUD and least was found to be sterilisation (6.5\%). But tubal ligation was found to be quite high $(61.9 \%)$ among all modern contraceptive methods, in South Bengal. ${ }^{7}$ Sterilization, as a method of contraception, was found to be $49 \%$ in Bankura district of West Bengal by another study conducted over a period of 3 months. ${ }^{12}$

Present study revealed that $14.50 \%$ of nonusers in the current study did not use contraception because of health concerns. Whereas barriers to the postpartum IUD insertion among the mothers, who delivered at the University of New Mexico, included provider advice against the IUD, patient failure to return for a postpartum visit. ${ }^{10}$ But a study conducted in rural Ghana found injectables (31.5\%) as most preferred methods, followed by exclusive breastfeeding (16.7\%), and oral contraceptive pills (14.8\%).

Acceptability of Postpartum Family Planning was determined by prior experience of the pregnant woman ,perception of partner acceptability . Prior experience with the use of injectables were the strongest predictors of the intention to adopt Postpartum Family Planning . ${ }^{11}$

In this study, $70 \%$ of contraceptive user was from study subjects of nuclear family, comparable to Bankura study conducted by Gupta A.et all. ${ }^{12}$ Several studies found that prevalence of contraception use increased as the educational level of the mothers and their socioeconomic status increased. ${ }^{7,13,14,15,16}$ But current study could not elicit them as significant variable. 
Only $66.42 \%$ of mothers were counselled regarding contraception during antenatal visit, which was less than the study conducted by Lauren B et al in Missouri, New York state, and New York City in 2015.( 78\%). ${ }^{17}$

The high prevalence of effective postpartum contraceptive use depends upon early visits and proper counselling, This intervention should start from antenatal period and to be continued till postpartum period and thereafter. More emphasis should be given to spacing methods, like Depot Medroxy Progesterone Acetate, Progestogen only Pill etc. Behaviour change communication not only helps in awareness generation but also improve attitude and practice of contraceptive methods. Thus target for population stabilisation can be achieved through these measures.

\section{References:}

1. https://www.who.int/news-room/factsheets/detail/family-planningcontraception accessed

2. Update to CDC's U.S. Medical Eligibility Criteria for Contraceptive Use, 2010: revised recommendations for the use of contraceptive methods during the postpartum period. MMWR Morb Mortal Wkly Rep. 2011 Jul 8;60(26):878-83 available

at
https://www.cdc.gov/mmwr/pdf/wk/mm60 26.pdf accessed 20.4.2019

3. Ndugwa RP, Cleland J, Madise NJ, Fotso J-C, Zulu EM. Menstrual Pattern, Sexual Behaviors, and Contraceptive Use among Postpartum Women in Nairobi Urban Slums. J. Urban Health 2011;88(S2):341355.

4. Rama Rao S, Ishaku S, Liambila W, Mane B. Enhancing contraceptive choice for postpartum women in sub-Saharan Africa with the progesterone vaginal ring: a review of the evidence. Open Access $J$ Contracept. 2015;6:117-123.

5. Programming Strategies for Postpartum Family Planning World Health
Organization

2013

https://www.who.int/reproductivehealth/pu blications/family_planning/ppfp_strategies /en/Accessed from WHO web site; accessed 28.04.2019.

6. International Institute for Population Sciences (IIPS) and ICF. 2017. National Family Health Survey (NFHS-4), 2015-16: India. Mumbai: IIPS.

7. Dr. Baijayanti Baur, Dr. Anima Haldar, Dr. Subhrajyoti Naskar, Dr. RamaPrasad Roy, Dr. Samir kumar Roy Sociobiological determinants of contraceptive practice in a district of West Bengal, India: An appraisal. JCH, Year: 2014Volume:2| Issue-2.

8. Sarah L Barber Family Planning Advice and Postpartum Contraceptive Use among Low-Income Women in Mexico International Family Planning Perspectives 2007; 33, No. 1: 6-12.

9. John A. Ross and William L. Winfrey Contraceptive Use, Intention to Use and Unmet Need during the Extended Postpartum Period International Family Planning Perspectives 2001; 27, No. 1: 20-27

10. Ogburn JA, Espey E, Stonehocker Barriers to intrauterine device insertion in postpartum women JContraception 2005; Volume 72 Issue 6: 426-429

11. Sebastian Eliason, Frank Baiden, Gloria Quansah Asare, Yvonne Graham-Hayfron, Derek Bonsu,James Phillips and Kofi Awusabo-Asare. Factors influencing the intention of women in rural Ghana to adopt postpartum family planning Reproductive Health 2013;10:34 https://doi.org/10.1186/1742-4755-10-34 accessed 28.4.2019

12. Avisek Gupta, Tapas Kumar Roy, Gautam Sarker, Bratati Banerjee, Somenath Ghosh, and Ranabir Pal Determinants of Contraceptive Practices Among Eligible Couples of Urban Slum in Bankura 
District, West Bengal J Family Med Prim

Care. 2014 Oct-Dec; 3(4): 388-392.

13. Kanoja JK, Nirbharvane NC. Dynamics of contraceptive practice among urban Indian women. Nat'1 Med J India 1996:109-12.

14. Tuladhar H,Marahatta R. Awareness and practice of family planning methods in women attending Gyne OPD at Nepal Medical College Nepal Med Coll J 2008;10(3):184-191.

15. Shah NM. Past and current contraceptive use in Pakistan. Study in FP 1979; 10:16473.

16. Singh et al Acceptability of contraceptive method among urban eligible couples of Imphal, Manipur. IJCM, 2004, 29(1):1317.

17. Lauren B. Zapata PhD, Sarah Murtaza MPH, Maura K. Whiteman PhD, Denise J.Jamieson MD, Cheryl L. Robbins PhD, Polly A. Marchbanks PhD, Denise V.D' Angelo MPH, Kathryn M.CurtisPhD Contraceptive counseling and postpartum contraceptive use American Journal of Obstetrics and Gynecology 2015 Volume 212, Issue 2, 171.e1-171.e8. 